\title{
Estimation of offshore extreme wind from wind-wave coupled modeling
}

Larsén, Xiaoli Guo; Du, Jianting; Bolaños, Rodolfo; Imberger, Marc; Kelly, Mark C.; Badger, Merete; Larsen, Søren

\section{Published in:}

Wind Energy

Link to article, DOI:

$10.1002 /$ we.2339

Publication date:

2019

Document Version

Peer reviewed version

Link back to DTU Orbit

Citation (APA):

Larsén, X. G., Du, J., Bolaños, R., Imberger, M., Kelly, M. C., Badger, M., \& Larsen, S. (2019). Estimation of offshore extreme wind from wind-wave coupled modeling. Wind Energy, 22(8), 1043-1057.

https://doi.org/10.1002/we.2339

\section{General rights}

Copyright and moral rights for the publications made accessible in the public portal are retained by the authors and/or other copyright owners and it is a condition of accessing publications that users recognise and abide by the legal requirements associated with these rights.

- Users may download and print one copy of any publication from the public portal for the purpose of private study or research.

- You may not further distribute the material or use it for any profit-making activity or commercial gain

- You may freely distribute the URL identifying the publication in the public portal 


\title{
Estimation of offshore extreme wind from wind-wave coupled
}

\section{modeling $\dagger$}

\author{
Xiaoli Guo Larsén*1 | Jianting Du, ${ }^{3,1}$ | Rodolfo Bolaños ${ }^{2}$ | Marc Imberger ${ }^{1}$ | Mark \\ Kelly ${ }^{1}$ | Merete Badger ${ }^{1}$ | Søren Larsen ${ }^{1}$
}

\author{
${ }^{1}$ Wind Energy Department, Technical \\ University of Denmark, Risø Campus, \\ Denmark \\ ${ }^{2} \mathrm{DHI}$, Denmark \\ ${ }^{3}$ current: The First Institute of Oceanography, \\ SOA, China \\ Correspondence \\ *Xiaoli Guo Larsén. Email: xgal@dtu.dk \\ Present Address \\ Frederiksborgvej 399, Building 125, 4000 \\ Roskilde, Denmark
}

\begin{abstract}
Summary
A coupled wind-wave modeling system is used to simulate twenty-three years of storms and estimate offshore extreme wind statistics. In this system, the atmospheric Weather Research and Forecasting (WRF) model and Spectral Wave model for Near shore (SWAN) are coupled, through a wave boundary layer model (WBLM) that is implemented in SWAN. The WBLM calculates momentum and turbulence kinetic energy budgets, using them to transfer wave-induced stress to the atmospheric modeling. While such coupling has a trivial impact on the wind modeling for 10-m wind speeds less than $20 \mathrm{~ms}^{-1}$, the effect becomes appreciable for stronger winds-both compared with uncoupled WRF modeling, as well as with standard parameterization schemes for roughness length. The coupled modeling output is shown to be satisfactory compared with measurements, in terms of the distribution of surface-drag coefficient with wind speed. The coupling is also shown to be important for estimation of extreme winds offshore, where the WBLMcoupled results match observations better than results from non-coupled modeling, as supported by measurements from a number of stations.
\end{abstract}

KEYWORDS:

Offshore, Extreme wind, Wind-wave coupled modeling, 50-year wind

\section{1 | INTRODUCTION}

More and more offshore wind farms are being built. Many of them will be located in coastal areas, i.e. tens of kilometers from the shore. Suitable wind turbines need to be chosen for each farm in order to harvest the most wind energy, while reducing the risk of damage from challenging wind conditions. In general, we lack long-term offshore wind measurements for the calculation of the extreme wind, e.g. the 50 -year wind $\mathrm{U}_{50 \mathrm{yr}}$ specified in the IEC standard $61400-1^{1}$. Numerical mesoscale modeling is becoming an important tool for this purpose, as it can provide decadeslong time series. This is seen as attractive for the estimation of extreme wind, which is often challenged by the lack of long-term data ${ }^{2,3,4}$. Being constrained by computational cost, mesoscale models are often set up at rather coarse resolutions (e.g. grid spacings greater than 5 km) for longterm simulations. A consequence of using coarse resolution is the considerable smoothing effect embedded in a mesoscale model, which manifests

${ }^{\dagger}$ Supported by Danish PSO-12020 X-WiWa project and EU CEASELESS project 
as reduced wind variation in the corresponding frequency/wavenumber range ${ }^{5,6,7,8}$. Such reduction directly leads to underestimation of extreme wind $^{8}$. Further, mesoscale simulations are often run for a period of the order of 10 days or longer after the initial forcing, which is practical and useful for obtaining long-term mean wind statistics; however, such a long simulation time increases the chance for a storm to drift away from the large-scale forcing, resulting in inaccurate calculation of storm statistics. The Selective Dynamical Downscaling Method (SDDM) developed in Larsén et al. ${ }^{9}$ puts modeling effort on storms that contribute to the calculation of extreme winds, allowing use of relatively high spatial resolution (with resolved scales as small as $2 \mathrm{~km}$ or less), which reduces the numerical smoothing effect. For a storm, the simulation only needs to cover its duration over a certain domain; over Denmark, for instance, this is usually shorter than 2 days. The short simulation period significantly reduces the chance of the storm development deviating from the large-scale forcing. The SDDM method is thus used in this study.

However, even with such a model set up, it is a challenge to model strong winds over water. This challenge is illustrated in Fig. 1, which shows the drag coefficient $C_{D}$ plotted as a function of wind speed at $10 \mathrm{~m}$ height $\left(\mathrm{U}_{10 \mathrm{~m}}\right)$, compiled from numerous studies. In numerical modeling, the momentum exchange between air and water is often described through $C_{D}$ or via the roughness length $z_{0}$. By definition, $C_{D}=u_{*}^{2} / U_{10 m}^{2}$, where $u_{*}$ is the friction velocity. For neutral conditions, assuming a logarithmic wind profile $U_{10 m}=\left(u_{*} / \kappa\right) \ln \left(z / z_{0}\right)$ in the neutral atmospheric surface layer, the relation between $C_{D}$ and $z_{0}$ is commonly expressed as

$$
C_{D}=\left(\frac{\kappa}{\ln \left(z / z_{0}\right)}\right)^{2},
$$

where $\mathrm{z}$ is the height and $\kappa=0.4$ is the von Kármán constant. For $\mathrm{U}_{10 \mathrm{~m}} \gtrsim 20 \mathrm{~ms}^{-1}$, neutral stability can be considered a reasonable assumption, given the small impact of stability on $\mathrm{U}$ at such low heights ${ }^{10}$.

The data shown in Fig. 1 were collected from a number of famous campaigns, including Powell et al. ${ }^{11}$, CBLAST $^{12}$, RASEX $^{13,14}$, COARE $^{15}$ and the wave tank experiment of Donelan ${ }^{16}$. It can be seen that for $\mathrm{U}_{10 \mathrm{~m}}<20 \mathrm{~ms}^{-1}$, different measurements suggest rather consistent dependence of $C_{D}$ on $U_{10 m}$, with $C_{D}$ exhibiting a moderate level of scatter around a given $U_{10 m}$. The commonly-used model for $C_{D}$, labeled in Fig. 1 as "Fairall" 15 , is based on the Charnock $z_{0}$ and smooth-flow $z_{0}$ for light winds:

$$
z_{0}=\alpha_{\mathrm{ch}} \frac{u_{*}^{2}}{g}+0.11 \frac{\nu}{u_{*}}
$$

where $\alpha_{\mathrm{ch}}$ is the Charnock parameter, and $\nu$ is the kinematic viscosity of water. The Fairall model was calibrated with measurements from the COARE experiment and it can be considered a reasonable approximation for most of the measurement groups, especially for $\mathrm{U}_{10 \mathrm{~m}}<20 \mathrm{~ms}^{-1}$. The Fairall form (2) is the default approach for $\mathrm{z}_{0}$ in the WRF model, where $\alpha_{\mathrm{ch}}=0.011$ for $\mathrm{U}_{10 \mathrm{~m}}<10 \mathrm{~ms}^{-1}$ and $\alpha_{\mathrm{ch}}$ is prescribed to increase linearly with $U_{10 m}$ to be 0.018 at $U_{10 m}=18 \mathrm{~ms}^{-1}$, and remain fixed at 0.018 for $U_{10 m}>18 \mathrm{~ms}^{-1}$. However, this model tends to overestimate $C_{D}$ for $\mathrm{U}_{10 \mathrm{~m}}>20 \mathrm{~ms}^{-1}$. Different measurements in Fig. 1 show that $\mathrm{C}_{\mathrm{D}}$ increases gently with $\mathrm{U}_{10 \mathrm{~m}}$ for $20<\mathrm{U}_{10 \mathrm{~m}}<30 \mathrm{~ms}^{-1}$, and for $30<\mathrm{U}_{10 \mathrm{~m}}<40 \mathrm{~ms}^{-1}$ $C_{D}$ levels off with $U_{10 m}$, followed by a certain degree of decrease with $U_{10 m}$. For $U_{10 m}>40 \mathrm{~ms}^{-1}$, measurements are mostly from only a few hurricane $\operatorname{cases}^{17}$. Here the scatter is so enormous that any simple description of $C_{D}$ through $U_{10 m}$ alone becomes untenable. It is argued that the spread of $C_{D}$ at a given strong wind speed is related to the wave conditions s, $19,20,21,22,23^{\text {. }}$

In the past decades, many studies have tried to introduce the wave impact by parameterizing the Charnock parameter $\alpha_{\mathrm{ch}}$ in terms of derived wave parameters. For instance, the Fan scheme 22 adds a dependence upon wave age $c_{p} / u_{*}$ (where $c_{p}$ is the wave phase velocity at the peak frequency of the wave spectrum), and Liu ${ }^{21}$ further includes $a u_{*}$-based correction factor for the effect of spray along with $c_{p} / \mathbf{u}_{*}$. There are also studies that directly describe $z_{0}$ using wave parameters, without using the base form of Eq. 2; e.g., the Oost scheme ${ }^{19}$ uses the wavelength at 
the peak frequency of the wave spectrum $\left(L_{p}\right)$ and inverse wave age $u_{*} / c_{p}$, while the Drennan-scheme ${ }^{20}$, parameterizes $z_{0}$ through $u_{*} / c_{p}$ and the significant wave height $H_{s}$. In the Taylor-Yelland ${ }^{18}$ scheme, $z_{0}$ is parameterized with $H_{s}$ and wave steepness $H_{s} / L_{p}$. The above schemes were derived and calibrated with field experiments in various places, mostly representing open sea conditions. Figure 2 demonstrates some of the challenges in using these parameterization schemes for strong wind conditions, as well as for coastal zones.

The simultaneous availability of standard turbulence and wave measurements from mast 2 at the offshore site Horns Rev I (hereafter denoted M2) and a nearby buoy has made it possible to compare the various schemes. Details of the measurements are given in section 2.2. Data from M2 are divided into two groups, one with wind from the sea to land and one with wind from land to the sea. The measurements show that for light winds, $\mathrm{z}_{0}$ decreases with $\mathrm{U}_{10 \mathrm{~m}}$, evoking smooth flow characteristics; for $7 \mathrm{~ms}^{-1}<\mathrm{U}_{10 \mathrm{~m}}<12 \mathrm{~ms}^{-1}$, the $\mathrm{z}_{0}$ is larger for flow towards offshore (land fetch) than onshore flow (open ocean fetch), consistent with the observations of Mahrt et al. ${ }^{13}$. For $\mathrm{U}_{10 \mathrm{~m}}>12 \mathrm{~ms}^{-1}$ the roughness levels off for the offshore flow; but for open-ocean (onshore) flow, $\mathrm{z}_{0}$ is seen to increase with $\mathrm{U}_{10 \mathrm{~m}}$ up to the maximum measured wind speed categories observed at M2 (about $23 \mathrm{~ms}^{-1}$ ).

In Fig. 2, the five aforementioned $z_{0}$ parameterization schemes are applied using the measured wave parameters from a buoy close to M2 (see section 2.2) and they are presented for the onshore and offshore data groups in solid and dashed curves, respectively. Clearly, since these schemes have been calibrated with open sea (deep water) data, they do not distinguish onshore from offshore conditions. Thus they conform only with the onshore data group for non-smooth flow (here at this site $U_{10 m}>7 \mathrm{~ms}^{-1}$ ). This reflects the limitations in these schemes for coastal zones. From Fig. 2 it can also be seen that for light to moderate winds $\left(\mathrm{U}_{10 \mathrm{~m}}<15 \mathrm{~ms}^{-1}\right)$, the variation in predicted magnitudes of $\mathrm{z}_{0}$ is small $\left(\mathrm{O}\left\{10^{-3} \mathrm{~m}\right\}\right)$. This means that using different models will not make significant impact on the calculation of wind speed. However, as wind speed increases, the differences between $\mathrm{z}_{0}$ predicted by different schemes increases, and becomes significant for $\mathrm{U}_{10 \mathrm{~m}}>15 \mathrm{~ms}{ }^{-1}\left(\mathrm{O}\left\{10^{-2} \mathrm{~m}\right\}\right)$. Accordingly, the calculation of the wind speed can be affected considerably by the choice of the schemes. This is the second issue with the use of the parameterization schemes. For a place like Denmark, the calculation of extreme wind is challenged by a number of factors. Here the extreme winds are caused by mid-latitude cyclones travelling across the North Sea, where $U_{10 \mathrm{~m}}$ can easily exceed $20 \mathrm{~ms}^{-1}$, and therefore there is a high uncertainty in using the standard parameterization schemes for $z_{0}$. Denmark is also surrounded mostly by water, i.e. bordered by coastlines. In the coastal area of many potential future offshore wind farms, the behaviors of $z_{0}$ can be different from the open sea conditions, due to coastal effects such as fetch, bathymetry, shoaling and wave-breaking processes.

A number of parameterization schemes for $z_{0}$, including those mentioned above, were examined in Du (2017) ${ }^{24}$ (Chap. 8) through case studies in comparison with calculations from a wave boundary layer model (WBLM). The WBLM was developed by Du et al. ${ }^{23}$ to couple the atmospheric Weather and Research Model (WRF) and Near-shore Spectral Wave model SWAN. Details of this WRF-WBLM-SWAN modeling system will be briefly introduced in section 3. Through the use of the WBLM, wave-induced stress is introduced to the atmospheric modeling without using derived wave parameters. It was also shown in Du (2017) ${ }^{24}$ that during storms, in terms of the $C_{D}\left(U_{10 m}\right)$ dependence and spread of $C_{D}$ at a given $U_{10 m}$, WBLM outperforms the other schemes. In comparison with the measurements shown in Fig. 1, it was shown in Du et al. ${ }^{23}$ that wave properties within the WBLM calculation can explain a significant part of the observed spread of $C_{D}$ at a given $U_{10 m}$ for high wind speeds $\left(U_{10 m}>20\right.$ ms $\left.{ }^{-1}\right)$.

Due to the promising performance shown by the WBLM for both coastal areas and strong wind conditions, this study uses the modeling system WRF-WBLM-SWAN to simulate storms that contributed to the extreme winds over Danish waters and calculate the 50-year return winds at a 
typical modern turbine hub height. The method is described in section 2 . The coupled modeling system is briefly introduced in section 3 . Results are given in section 4, followed by discussions and conclusions in sections 5 and 6 , respectively.

\section{2 | METHOD}

\section{1 | The selective dynamical downscaling method}

We use the selective dynamical downscaling method as developed in Larsén et al. ${ }^{9}$ to calculate the extreme wind. This method puts modeling effort on storms that contribute to the extreme wind samples. The first step of this method is to identify storm episodes from coarse resolution reanalysis data. This forms the collection of storms to be downscaled using high resolution mesoscale modeling. In this study we use the $10 \mathrm{~m}$ wind speed from the Climate Forecast System Reanalysis selected hourly products (CFSR) datasets I (from 1979-2010) and II (2011-present) for identifying the storms in the period 1994-2016. The CFSR data are hourly, and the $\mathrm{U}_{10 \mathrm{~m}}$ data from CFSR-I and II have spatial resolutions of about $38 \mathrm{~km}$ and $25 \mathrm{~km}$, respectively.

We intend to make an extreme wind atlas over the area of the inner-most model domain (III) shown in Fig. 3. Domain III includes 735 grid points for CFSR I data and 1728 grid points for CFSR II data. At each grid point, the annual wind maxima and their corresponding dates are identified. These dates are merged, suggesting a total of 321 storms for the period $1994-2016$. This corresponds to about $5 \%$ of the computation cost of a climatological simulation for this 23-year period. The storm data are downscaled to $2 \mathrm{~km}$ resolution using the WRF model only, as well as using the WRF-WBLM-SWAN coupled system (section 3). The model outputs are saved every 10 min. For domain III, there are 339 by 342 grid points at spatial resolution of $2 \mathrm{~km}$ (section 3.1). We exclude the first 5 rows of data, since they are calculated here in the nudging zone. For each grid point, 23 annual wind maxima from 1994 to 2016 will be obtained from the storm modeling and they will be used as samples to a Gumbel distribution to obtain the 50-year value $U_{50 y r}$ (section 2.3).

\section{2 | Measurements}

Long term measurements from offshore stations are rare. This is also the case for the waters around Denmark. We collected measurements from five sites: FINO 1, 2 and 3, Høvsøre and Horns Rev I mast 2 (hereinafter M2). They are all inside model domain III, see Fig. 4. Høvsøre is actually land-based with a distance of about $1.7 \mathrm{~km}$ to the coast; at a height of $100 \mathrm{~m}$, the winds from the west represent sea condition, as is the case here.

The calculation of $U_{50 y r}$ is strongly affected by data length and data coverage of the strongest winds. The relatively long time series are from Høvsøre and FINO 1, being 13 and 14 years and the shortest time series is from M2 where only 6 years of data are available, see Table 1. The effect of the data length and its climatological representativeness on the calculation of the 50-year wind will be shown and discussed in sections 2.3 and 4. The yearly data coverage for each of the five sites is plotted in Fig. 5. During the strongest winds, the technical challenges are highest, leading to failures in collecting the data. Missing the most relevant strong wind samples in relation to the use of the Periodic Maxmum Method (PMM) and Peak-Over-Threshold method (POT) (see section 2.3) will lead to underestimation of $\mathrm{U}_{50 y r}$.

We address winds at $100 \mathrm{~m}$ above sea level, corresponding to typical multi-megawatt wind turbine hub heights, and analyze the 50 -year wind at $z=100 \mathrm{~m}$ (except for M2, which has its highest measurement level at $62 \mathrm{~m}$ ). The description of measurements from the FINO masts can be found in $25,26,27,28,29$, and Høvsøre is detailed in Peña ${ }^{30}$ and Larsén et al. ${ }^{31}$. 
As will be discussed in Sec. 4.1, short-term measurements from Horns Rev I (M2 and buoy) is limited for an accurate estimation of $U_{50 y r}$, it is though useful for examining the relationship between wind and wave parameters, as shown in Fig. 2. Details of the wind measurements can be found e.g. in Larsén et al. ${ }^{32}$. Details of the wave measurements from this site can be found in Saint-Drenan ${ }^{33}$. Briefly, the wave data were collected from a buoy ("Wave Rider S", $\left.7.5298^{\circ} \mathrm{E}, 55.4798^{\circ} \mathrm{N}\right)^{33}$, close to the meteorological mast M2. The water depth (D) at the buoy site varies from 6 to $12 \mathrm{~m}$, which can be considered as intermediate to shallow water according to the distribution of the ratio of water depth and the peak wave length $\mathrm{L}_{\mathrm{p}}{ }^{34}$. The waves were measured through the vertical acceleration of the buoy. From the measured one-dimensional wave power spectrum, the significant wave height $\mathrm{H}_{s}$ was derived using 30-min time series. By taking D into consideration, the wave phase velocity $c_{p}$, peak wave period $T_{p}$ and wave length $L_{p}$ were calculated. These wave parameters are used in the parameterization schemes, shown in Fig. 2. The dots are measurements with $\mathrm{z}_{0}$ calculated using the profile and flux measurements, via Monin-Obukhov Similarity Theory:

$$
z_{0}=z \cdot e^{-\kappa U(z) / u_{*}+\Psi_{m}}
$$

where $\Psi_{\mathrm{m}}$ is the stability correction function ${ }^{35,36}$. Note that the turbulence measurements (e.g. $\mathrm{u}_{*}$ ) were taken at $50 \mathrm{~m}$ above the sea surface, so in applying (3), $z=50 \mathrm{~m}$. In the plot of Fig. 2, the 10-m wind speed $\mathrm{U}_{10 \mathrm{~m}}$ was calculated using measurements from $15,30,45$, and $62 \mathrm{~m}$ using second order polynomial fitting. We chose not to use Eq. 3 to obtain $U_{10 m}$ to avoid self-correlation when presenting the distribution of $z_{0}$ with $\mathrm{U}_{10 \mathrm{~m}}$. In this figure, both atmospheric and wave parameters are obtained from 30-minute averages. These data are from 1999 to 2006 , with the data coverage from 2000 to 2005 given in Fig. 5 (there was less than half a year of data for 1999 and 2006). In Fig. 2, the 30-min values are first grouped into bins of $U_{10 m}$ having width $0.2 \mathrm{~ms}^{-1}$, and the mean of $\ln \mathrm{z}_{0}$ and $\mathrm{U}_{10 \mathrm{~m}}$ from each bin are used to plot Fig. 2.

\section{3 | Calculating the 50-year wind}

Shorter measurement time series lead to higher uncertainty in the estimate of $\mathrm{U}_{50 \mathrm{yr}}{ }^{37,38}$. To have a better evaluation of this uncertainty, two approaches are used, namely the Period Maximum Method (PMM) and the Peak-Over-Threshold method (POT).

Derivations of the T-year return wind $\mathrm{U}_{\mathrm{T}}$ using PMM and POT can be found in e.g. Abild ${ }^{37}$ and Larsén et al. ${ }^{38}$. Here we list relevant algorithms for the calculation of $U_{50 y r}$ and the uncertainty in fitting a Gumbel distribution. By applying the Gumbel distribution, for $\mathrm{T}>>\mathrm{T}_{\mathrm{BP}}$, the corresponding algorithms for $\mathrm{U}_{\mathrm{T}}$ using $\mathrm{PMM}$ can be approximated as:

$$
U_{T}=\alpha^{-1} \ln \left(T / T_{B P}\right)+\beta
$$

where $\mathrm{T}_{\mathrm{BP}}$ is the basis period, over which the maxima $\mathrm{U}^{\max }$ are identified. The coefficients $\alpha$ and $\beta$ can be obtained through various methods; here we use the probability-weighted moment procedure ${ }^{37,39}$ :

$$
\alpha=\frac{\ln 2}{2 b_{1}-\overline{U^{\max }}}, \quad \beta=\overline{U^{\max }}-\frac{\gamma_{E}}{\alpha},
$$

where $\gamma_{E} \approx 0.577215665$ is Euler's constant, and $\overline{U^{\max }}$ is the mean of $U_{i}^{\max }$. The coefficient $b_{1}$ is calculated via

$$
b_{1}=\frac{1}{n} \sum_{i=1}^{n} \frac{i-1}{n-1} U_{i}^{\max } .
$$

Mann et al. ${ }^{40}$ gave the standard error of the Gumbel fitting in obtaining $U_{\mathrm{T}}$ from the standard deviation of $U^{\max }$ as

$$
\sigma\left(U_{T}\right)=\frac{\pi}{\alpha} \sqrt{\frac{1+1.14 k_{T}+1.10 k_{T}^{2}}{6 n}},
$$


where a Gaussian distribution of the error in estimate of $U_{T}$ is assumed and the coefficent $k_{T}$ can be re-written as

$$
k_{T}=-\frac{\sqrt{6}}{\pi}\left[\ln \ln \left(\frac{1}{1-T / T_{B P}}\right)+\gamma_{E}\right] .
$$

If we assume the estimate of $\mathrm{U}_{\mathrm{T}}$ also a Gumbel distribution, the estimate of $\sigma\left(\mathrm{U}_{\mathrm{T}}\right)$ will be systematically about $10 \%$ smaller than the use of Eq. $7^{41}$.

The corresponding algorithms for calculating $\mathrm{U}_{\mathrm{T}}$ using POT read:

$$
U_{T}=u_{0}+A \ln (\lambda T)
$$

where $A$ is a scale factor and it can be obtained from the fitting of samples, $\lambda$ is the exceedance rate per base period (e.g. 1 year) corresponding to a threshold $\mathrm{u}_{0}$. Eq. 9 can be written in a form similar to Eq. (4):

$$
U_{T}=A \ln T+B
$$

with $\mathrm{B}=\mathrm{u}_{0}+\mathrm{A} \ln \lambda$. Mann et al. ${ }^{40}$ and $\mathrm{Abild}^{37}$ used the Poisson process and properties of the exponential distribution, and obtained the uncertainty in relation to fitting Eq. 9:

$$
\sigma\left(U_{T}\right) \approx \frac{A}{\sqrt{\lambda T_{\text {tot }}}} \sqrt{1+\ln ^{2}(\lambda T)},
$$

where $T_{\text {tot }}$ is the total length (in time) of the data. For large samples, Larsén et al. ${ }^{38}$ show that the values of $A$ and B from POT in Eq. 10 are comparable with $\alpha^{-1}$ and $\beta$ from PMM in Eq. 4.

For the modeled data produced in this study, in connection with the selective dynamical downscaling method which focuses on the annual wind maxima, we apply $\mathrm{PMM}$ with $\mathrm{T}_{\mathrm{BP}}=1$ year; this is also commonly referred to as the annual maximum method (AMM). For measured time series, as mentioned earlier, due to limited data length and incomplete data coverage, we use both POT and PMM to systematically check for consistency in the 50-year value calculations and, in case of discrepancy between the two methods, the uncertainties will be analyzed and recommendations made.

When applying POT to the measurements, we use an interval of one week to separate consecutive events, to ensure the samples to be independent of each other. At the same time, following Larsén et al. ${ }^{38}$, a series of threshold $\mathrm{u}_{0}$ are used, starting with the smallest annual wind maximum, and ending with the value corresponding to a decrease of $\lambda$ to 2 per year. The estimate will have to pass the examination of goodness-of-fit where the maximum deficiency of the fitted probability distribution function is within the $95 \%$ confidence level. We use the mean of the estimates as the final value of $U_{50 y r}$ from POT, where a number of $u_{0}$ are used. The number of $u_{0}$-values at these sites is between 5 and 7 , suggesting that the final estimate is based on 5 to 7 independent calculations.

When applying PMM to the measurements, considering the relatively short period (only two sites have measurements longer than 10 years), we use $\mathrm{T}_{\mathrm{BP}}=6$ months, in order to have more samples than using $\mathrm{T}_{\mathrm{BP}}=1$ year. As discussed in Larsén et al. ${ }^{38}$, for the sites in this area, both the extreme wind events from the first and second half of the year are from the Atlantic lows in winter time and it is therefore reasonable to use $\mathrm{T}_{\mathrm{BP}}=6$ months. One of the main conclusions from Larsén et al. ${ }^{38}$ is that limited length of measurements can limit the climatological representativeness, resulting in biased estimates of $U_{50 y r}$. This discussion will become relevant when we validate estimates from 23 years of modeled data with those from measurements with half or less than half of the data length (see Section 5). 


\section{3 | THE MODELING SYSTEM}

\section{1 | Model setup of WRF and SWAN}

When we use the WRF model to model a storm, the quality of the output is affected by many factors. Sensitivity studies have been done and the results have been presented in Du et al. ${ }^{42}$ and Imberger ${ }^{43}$. It was found that factors affect the modeling of the mid-latitude cyclones over the North Sea include the size of the domain, the position of the domain in relation to the path of the storm, the initial time of the modeling, the simulation period and the spatial resolution. Du et al. ${ }^{42}$ and Imberger ${ }^{43}$ suggest that (1) the outer model domain should be big enough to ensure that the storm center is passing the domain; but the domain should not be too big to prevent the mesoscale model from developing its own dynamics that deviate from the large scale forcing, over the space; (2) using a simulation period of 36 hours gives better calculation of storm peak wind speed than using 72 hours. Both time spans refer to the total simulation time inclusive 12-hour spin-up period. This is also argued to prevent the mesoscale model from developing its own dynamics from the large scale forcing through time; (3) spectral analysis in Imberger ${ }^{43}$ suggests a spin-up time of 12 hours is sufficient for the model to build up to model layers close to the top. The only exception remained for the top-most model level (unstagged) which showed lower energy in the spatial spectrum for angular wave numbers in the range above $10^{-5} \mathrm{~m}^{-1} \cdot \mathrm{rad}$, compared to the other vertical levels. The difference at the top level is likely to be caused by the close location to the end of the WRF model domain in z-direction, which sets an artificial boundary to the flow. Therefore, information obtained from this level have to be interpreted with caution; (4) the spectral analysis also suggests that in order to capture the wind variability of the storms passing Denmark, a spatial resolution of $2 \mathrm{~km}$ or higher is necessary. (5) Imberger ${ }^{43}$ also found that if the location where a storm enters the model domain is very close to the corner, the storm will not develop properly, and will result in underestimation of storm intensity as shown in the mean sea level pressure values.

The above findings are used to guide our model setup. Fig. 3 shows the three model domains. In WRF we used two-way nesting for the three domains, with spatial resolutions of 18,6 and $2 \mathrm{~km}$, for domains I, II and III, respectively. There are 52 vertical (sigma) levels for all three domains, with the lowest model level at a height of about $10 \mathrm{~m}$, with a vertical interval of about $10 \mathrm{~m}$ up to $100 \mathrm{~m}$. We used the Thompson microphysics scheme ${ }^{44}$, RRTM long and short wave radiation physics scheme ${ }^{45}$ and MYNN 3.0 PBL scheme ${ }^{46}$. The Kain-Fritsch cumulus scheme ${ }^{47}$ was used for the outer domain (I) but not for domains II and III. The Corine land use data are employed for the land surface, and CFSR data are used as the initial and boundary forcing for WRF. The daily $0.25^{\circ}$ OISST data were used. Each simulation lasts 36 hours, with the first 12 hours in the spinning-up time disregarded. The 321 storms passing domain III, with some lasted more than one day, result in 429 simulations and hence 429 days.

SWAN is a third-generation wave model, developed at Delft University of Technology, that computes random, short-crested wind-generated waves in coastal regions and inland waters ${ }^{48}$. The model domain and grid setup for SWAN is the same as for WRF, with three nested domains as shown in Fig. 3. In SWAN, the 1/8 arc-minute bathymetry data from EMODnet Digital Terrain Model (DTM) are used. SWAN is initiated with output spectrum of a previous SWAN simulation 24 hours before. The open boundaries of the outer domain are set to zero. We used 36 directional bins.

The frequency exponent is 1.1, the lowest frequency is set to be $0.03 \mathrm{~Hz}$, and the maximum frequency is $10.05 \mathrm{~Hz}$, which gives $61 \mathrm{frequencies}$ in total. The time step for SWAN is 5 minutes.

WRF and SWAN are coupled using the framework of COAWST through the Model Coupling Tool (MCT). The interface is the wave boundary layer model (WBLM) developed in Du et al. (2017) ${ }^{23}$, which will be introduced in section 3.2 . WRF sends the wind components $\mathrm{u}_{10 \mathrm{~m}}$ and $\mathrm{v}_{10 \mathrm{~m}}$ to SWAN and SWAN sends back stress calculation every 5 minutes. 


\subsection{The interfacial Wave Boundary Layer Model and coupled system}

Janssen et al. introduced a method to couple wave modeling to atmospheric modeling, through a wave boundary layer (WBL). ${ }^{49}$ The WBL serves as an interface where the wave induced stress $\tau_{\mathrm{w}}$ is one component of the total stress $\tau_{\text {tot }}$, and

$$
\tau_{\text {tot }}=\tau_{w}+\tau_{t}+\tau_{\nu}=\text { constant }
$$

with $\tau_{\mathrm{t}}$ the stress due to atmospheric turbulence and $\tau_{\nu}$ the viscous stress. In the WBL, $\tau_{\nu}$ becomes negligible a few centimeters above the water surface, $\tau_{\mathrm{t}}$ increases with height and $\tau_{\mathrm{w}}$ decreases with height and becomes negligible at the top of WBL. There have been many studies following and improving this approach, with one common purpose particularly to solve the reported overestimation of wind stress in strong wind conditions $^{50,51,52}$.

To reduce the growth rate and therefore the modeled stress, a number of research groups developed a method to link the growth rate of the short wind waves to the sheltering effect from longer waves ${ }^{53,54,51}$. The momentum conservation and sheltering effect are described through the WBLM. In the literature, the WBLM has been used to calculate the surface stress, but it is not linked to the wind-input source function for the wave model. This means that the wave growth in the WBLM is not consistent with the growth in the wave model. As a result, in the models the momentum loss from the atmosphere is not exactly the same as the momentum gained by the waves.

Du et al. ${ }^{23}$ implemented the WBLM within the SWAN model, to improve SWAN under fetch-limited conditions on wave simulation and stress estimation. Thus, WBLM and SWAN share the same wind-input source function, which ensures that the momentum flux from and to the atmospheric modeling is consistently calculated. The details of the WBLM in SWAN can be found in Du et al. ${ }^{23}$. Briefly, the WBLM in SWAN contains two conservation equations which describe the variation of stress and kinetic energy with height. Du et al. ${ }^{23}$ employed a sheltering mechanism, which suggests that the growth of short waves is reduced by low frequency waves; they also modified the Janssen source function by relating $\tau_{\mathrm{t}}$-instead of $\tau_{\text {tot }}-$ to the wave growth rate.

\section{4 | RESULTS}

\section{1 | 50-year winds from measurements}

The 50-year winds $\mathrm{U}_{50 \mathrm{yr}}$ are calculated from measurements for the five sites, using both the PMM and POT methods. The results are shown in Table 2, together with the uncertainty in relation to the Gumbel fitting, from Eq. 7 and Eq. 11 for PMM and POT, respectively.

The estimates from PMM and POT are comparable for measurements from FINO 1, Høvsøre and M2, where the difference in $\mathrm{U}_{50 y r}$ is much less than $\sigma\left(\mathrm{U}_{\mathrm{T}}\right)$. The differences are however a lot larger at FINO 2 and 3, and being comparable to or larger than $\sigma\left(\mathrm{U}_{\mathrm{T}}\right)$. The fitting uncertainty is in general smaller when using POT, due to more samples are collected. Note that, compared with FINO 2 and 3 , the data lengths at FINO 1 and Høvsøre are longer and data coverage in general larger. This may have attributed to the better agreement between the estimates from the two methods.

At $\mathrm{M} 2$, the uncertainty $\sigma\left(\mathrm{U}_{\mathrm{T}}\right)$ is largest due to the shortest measurements (6 years). At this site, the estimate is also troubled by low data coverage, which for some years is only about 75\% (Fig. 5). A particular storm on the 3rd Dec of 1999 affected this site significantly ${ }^{55}$, causing instrumental failure for 10 days after the storm peak. At $62 \mathrm{~m}$, the recorded 10 -min mean value at the storm peak is $45.4 \mathrm{~ms}^{-1}$, which is higher 
than the 50-year wind estimated using 6-year measurements excluding this case, for which $U_{50 y r}=44.8$ ms ${ }^{-1}$. Including this case in such a short time series introduces large uncertainty in the Gumbel fitting, and it gives a very different value: $U_{50 y r}=51.8$ ms $^{-1}$. It should be taken with caution when the estimation is highly sensitive to one single sample. In the following, discussions regarding the exact value of $U_{50 y r}$ will weight less on this site. The estimates from measurements shown in Table 2 and 3 are obtained excluding this storm.

The climatological representativeness of the measurements is an important factor to an accurate estimate of the 50 -year wind ${ }^{38}$. Are the measurements from these sites long enough for such an estimate? This issue is investigated with the help of the long term CFSR data. In Fig. 6 , the annual wind maxima from various data are plotted. Note that the purpose of this figure is not to discuss the exact value of $U^{m a x}$, but to show the long-term representativeness of the data we have through the inter-annual variation of $U^{\text {max }}$. The longest is the CFSR data of the 10- $m$ wind; we multiplied it by 1.3 for visual effect, so that the magnitude is comparable to the other data. Measurements and output at $100 \mathrm{~m}$ from coupled and uncoupled modeling are also plotted. From this figure, it can be seen that: (1) there is an oscillation of $U^{\max }$ with a period varying from about 5 years to 10 years, which is consistently shown by all data sets; (2) the peak values in some years are significantly larger than some other years; (3) FINO 1 measurements (Fig. 6a) cover 2 periods of the oscillation and FINO 3 measurements (Fig. 6b) cover less than one oscillation of the inter-annual variability. To see the impact of using different lengths of data on the estimate of $\mathrm{U}_{50 \mathrm{yr}}$, we used the CFSR 10 -m wind speeds for the following periods: 1979-2016 (entire CFSR data); 1994-2016 (our simulation); 2007-2016 (last 10 years referring to measurements) and the results are shown in Table 4. It can be seen that for these sites, the period 1994-2016 gives almost the same estimate as the period 1979-2016, while using the 10 years of data from 2007-2016 gives almost the same estimates for FINO 1, Høvsøre and M2, but the estimate is significantly smaller than using period $1994-2016$ or $1979-2016$.

This suggests that using the periods of measurements from FINO 2 and FINO 3 will lead to underestimation of $\mathrm{U}_{50 \mathrm{yr}}$, compared with using 20 years or longer time series, whilst using the periods of measurements from Høvsøre and FINO 1 is expected to give estimates close to that using 20 years or longer time series. The estimates from POT are based on several independent calculations using a series of $\mathrm{u}_{0}$, and the values of $\mathrm{U}_{50 \mathrm{yr}}$ are slightly higher than those from PMM. Considering the general tendency of underestimation using the limited measurements in these periods here, we choose to use the estimates from POT for further analysis.

\section{2 | The 50-year winds from modeling and validation}

The agreement in the estimate of $U_{50 y r}$ of using period 1994-2016 and 1979-2016 in Table 4 supports that our choice of modeling of the period 1994-2016 provides samples representative of long term extreme wind climate.

The selection of samples in the selective dynamical downscaling method is successful, as supported by the following analysis. We identified the dates of the yearly maximum winds from the measurements at the five sites. For the 51 sample dates (six from M2, 14 from FINO 1, ten from FINO 2, eight from FINO 3 and 13 from Høvsøre), there is only one missing. This missing day is 2008-03-21 from FINO 2 (with U max $^{\text {max }} 27.08$ ms ${ }^{-1}$ ); in our samples, the corresponding event was on 2008-03-01 for this site, with $U^{\max }=26.67 \mathrm{~ms}^{-1}$, which is rather close to that from 2008-03-21.

Model outputs from the 321 storms are first validated through the distribution of $C_{D}$ with $U_{10 m}$. In Fig. 7 , $C_{D}$ is calculated from the model outputs of $\mathrm{u}_{*}$ and $\mathrm{U}_{10 \mathrm{~m}}$ and plotted as a function of $\mathrm{U}_{10 \mathrm{~m}}$ for the four offshore sites (FINO 1, 2 and 3, and M2), together with measurements from the literature from Fig. 1 for $\mathrm{U}_{10 \mathrm{~m}}<35 \mathrm{~ms}^{-1}$. The color scale shows the number of 10-min data at each point. For all sites, although the largest data group lies above the COARE curve, the spread of $C_{D}$ is mostly within one standard deviation within each wind bin. The result can be considered in 
reasonably good agreement with the measurements in the literature, including the level of scatter of $C_{D}$ at a given $U_{10 m}$, which in our modeling is a result of varying wave conditions at this given wind speed. It is also noticeable that, at winds higher than $25 \mathrm{~ms}^{-1}, C_{D}$ levels off with wind speed, giving smaller drag compared to the default $z_{0}$ scheme in a non-coupled, WRF-only modeling. This accordingly results in higher wind speeds in the coupled modeling than in the non-coupled modeling. Over the entire domain, for $U_{10 m}>20 \mathrm{~ms}^{-1}$, the wind speed has shown to be systematically larger using the coupled model system in comparison with uncoupled modeling, and the difference increases with increasing wind speed.

The modeled data from the 321 storms, equivalent to 429 storm days, are aggregated to first find the annual wind maxima for each model grid in domain III. In a survey of these storms ${ }^{56}$, it was found that open cellular structure (open cells) was present in the modeled wind field over the water in $45 \%$ of the 429 days. Figure 8 shows an example of the wind field in the presence of open cells, with Fig. 8 a from modeling and Fig. $8 \mathrm{~b}$ retrieved from satellite Synthetic Aperture Radar (SAR) observations that cover the northwest part of the domain in Fig. 8a. The SAR data is from Sentinel-1B by the European Space Agency (ESA). Note that in Fig. 8b the color scale is different from Fig. 8a for visual purpose. It is known that the uncertainty of the SAR wind greater than $30 \mathrm{~ms}^{-1}$ is large ${ }^{57}$, though the spatial pattern shown in the data is useful to validate the spatial structure of wind in the presence of the open cells. Bakan and Schwarz ${ }^{58}$ reported that the average diameter of open cells is $41 \mathrm{~km}$ with a standard deviation of $15 \mathrm{~km}$, although the size depends on the observed latitude: cases with diameters of $20-30 \mathrm{~km}$ prevail north of $70^{\circ} \mathrm{N}$, while diameters of $50-60 \mathrm{~km}$ are most abundant south of $60^{\circ} \mathrm{N}$. A summary of the characteristics of the open cells over the North Sea can be found in Larsén et al. ${ }^{59}$, where it was also shown that the wind fields in the presence of open cells are characterized by large spatio-temporal fluctuations in the wind speed. Whilst mesoscale modeling can capture the size, propagation and wind fluctuation of open cells ${ }^{60,61,62}$, the exact locations of these cells are difficult to model. This results in the predicted location of related hot and cold spots (see Fig. 8a) potentially being shifted by an distance similar to the size of the convective cells. One needs to be aware of such an uncertainty of the spatial location of the hot spots of wind speed, when comparing modeled value (or subsequent statistics) for any particular time or space with the point measurements.

The yearly wind maxima have been extracted for each grid point from both the WRF-WBLM-SWAN coupled modeling and the uncoupled WRF modeling. The 50 -year winds $U_{50 y r}$ are obtained from the 23 samples for each grid point and the results for $\mathrm{z}=100 \mathrm{~m}$ are presented in Fig. $9 \mathrm{a}-\mathrm{b}$ for the coupled and uncoupled modelings. The model estimates are compared with measurements for the five sites and the results are shown in Table 2 and 3, as well as in Fig. 10a and b. In Table 2 and Fig. 10a, the entire time series from model data as well as from measurements are used. In Table 3 and Fig. 10b, we refer to the measured and modeled data from their overlapping period. Following discussions given in section 4.1, we use the measurement estimates using POT in Fig. 10. Both Fig. 10a and b show that the estimates from coupled modeling are closer to the measured estimates than the uncoupled modeling, except for M2 where the coupled and uncoupled simulations give the same results, as can also be seen in Fig. $9 \mathrm{c}$ and $\mathrm{d}$. For the coupled modeling, predicted $\mathrm{U}_{50 \mathrm{yr}}$ are comparable to the measured values at three sites and two are underestimated. For the uncoupled modeling, $\mathrm{U}_{50 \mathrm{yr}}$ were more underestimated.

Figure 9c shows the difference, $\Delta U_{50 y r, 100 m}$, between Fig. 9a and b (a minus b). Note that the the pattern of the hot spot of wind difference in Fig. $9 \mathrm{c}$ is a result of the superposition of individual open cell wind fields. As discussed earlier, an estimate of the uncertainty related to modeling the exact location of the open cells and thereof the hot spots is on the order of the cell sizes. We herein make a smoothing of the wind difference in Fig. $9 \mathrm{c}$ by using the maximum value of $\Delta \mathrm{U}_{50 \mathrm{yr}, 100 \mathrm{~m}}$ over 12 by 12 grid boxes, namely, $24 \mathrm{~km}$ by $24 \mathrm{~km}$ in area. The result is an upscaled $\Delta \mathrm{U}_{50 \mathrm{yr}, 100 \mathrm{~m}}$ over an area approximately with a diameter of $24 \mathrm{~km}$ and it is shown in Fig. 9d. The largest difference is present in the northwest part of domain III where the wind speed is strongest and here $\Delta U_{50 \mathrm{yr}, 100 \mathrm{~m}}$ ranges from about 2 to $4.5 \mathrm{~ms}^{-1}$. Referring to the IEC standard ${ }^{1}$, at a wind speed of 42 
to $48 \mathrm{~ms}^{-1}$ (Fig. 9a and b), a difference in $U_{50 y r}$ of 2 to $4.5 \mathrm{~ms}^{-1}$ can lead to different choice of wind turbine, which has a substantial economical impact.

\section{5 | DISCUSSION}

In connection with calculating offshore extreme winds, one of the biggest challenges in numerical modeling is to account for the impact of surface waves in the storm wind calculations. The most common way is to use algorithms derived from measurements over various water bodies. Whilst there is a consensus on how the momentum exchange occurs for winds up to $20 \mathrm{~ms}^{-1}$, a simple description using wind speed alone becomes ambiguous and inadequate for stronger winds. There are a number of parameterization schemes for $\mathrm{z}_{0}$ using derived wave parameters, some of which are shown in Fig. 2. For strong winds, these schemes deviate from each other, which can give significantly different estimates of $z_{0}$, and thus the wind speed.

To introduce the wave impact, we use a recently developed wind and wave coupled modeling system from Du et al. ${ }^{23}$ which transfers waveinduced momentum into the atmospheric modeling. The interface of the atmospheric and wave modeling is the so-called wave boundary layer (WBL). Du et al. implemented a wave boundary layer model (WBLM) inside the SWAN model. For the storms studied here, the $10 \mathrm{~m}$ winds $\mathrm{U}_{10 \mathrm{~m}}$ do not reach hurricane strength. For $U_{10 m}$ up to about $35 \mathrm{~ms}^{-1}$, the distribution of the drag coefficient $C_{D}$ with $U_{10 m}$ from the modeling can be considered satisfactory, including (1) data falling within error bars from measurements in the literature, (2) the level of spread of $C_{D}$ at a given $\mathrm{U}_{10 \mathrm{~m}}$ is comparable to measurements, and (3) $C_{\mathrm{D}}$ starts to level off with $\mathrm{U}_{10 \mathrm{~m}}$ at $\mathrm{U}_{10 \mathrm{~m}}$ about $20 \mathrm{~ms}^{-1}$ for the three FINO sites. The levelling-off is however not so clear at M2, and further investigation is needed on how the coastal wave conditions differ there from those open sea data.

The effect of using the coupled modeling, in comparison with using the stand-alone WRF modeling, is most obvious for winds stronger than $20 \mathrm{~ms}^{-1}$. This affects the calculation of the extreme winds, and the largest effect is seen over the water between Denmark and Norway, northwest of Jutland where winds are strongest. The difference in the 50-year wind at $z=100 \mathrm{~m}$ between coupled and uncoupled modeling can reach 4 $\mathrm{ms}^{-1}(\sim 10 \%)$, which is enough to affect the choice of turbine design from one class to another.

The results from the coupled and uncoupled modeling are validated through measurements. In calculating the 50-year wind using measurements, we face two major challenges: too few stations and not long enough data. For the five stations, the data lengths are 6, 8, 10, 13 and 14 years. The effect of climatological representativeness of these data and their period is examined through analysis using 38-year CFSR data (1979-2016). It was found that the data periods of FINO 2 (2008-2017) and 3 (2010-2017) are expected to underestimate U50yr, those of FINO 1 (2004-2017) and Høvsøre (2005-2017) are supposed to give similar estimates to using the 36-year data. The use of the CFSR data also suggest that the 23 years of storms (1994-2016) modeled here are expected to give similar estimates to using a 36-year data set.

Based on the 23 years of extreme wind storms, the coupled modeling provides closer estimates of $U_{50 y r}$ to the measurements than the uncoupled modeling, although there is still a degree of underestimation in the estimates from the coupled-modeling. Different methods have been applied to the modeled and measured data in obtaining $\mathrm{U}_{50 \mathrm{yr}}$. For the measured data, the purpose is to obtain as reliable as possible $\mathrm{U}_{50 \mathrm{yr}}$, so that both POT and PMM are used, and in connection with PMM, a base period of 6 months is used in order to reduce the sampling uncertainty. For the modeled data, the use of the annual form of PMM is implemented in the Selective Dynamical Downscaling Method (SDDM), where the sample number is sufficiently large, as also supported by the analysis of CFSR data. 
The SDDM is an efficient and robust method. It uses about $5 \%$ of the computational time required for a climatological simulation containing these storms. The SDDM thus allows us to use a rather expensive model setup with high spatial resolution, here $2 \mathrm{~km}$, to capture the spatial wind variability. Such a high spatial resolution is necessary for capturing the storms over the North Sea, where organized atmospheric features (e.g. open cellular structures) occur frequently in company with the storms. In these conditions it is wrong to assume that ocean surface is smooth and the wind field homogeneous.

A modeling system for calculating both winds and waves is important for a range of offshore applications. The reliability of such modeling is particularly important for severe wind and wave conditions, which has relevance in applications such as offshore traffic, wind farm operation and maintenance-as well as in wind farm design choices like those addressed by the current study.

In this study most storms had prevailing winds from the west, i.e. from sea to land. There are only very limited periods where the winds are from land to sea, and during these periods the wind fields changed rapidly with time. We thus lack a sufficient sample set to examine the dependence of $\mathrm{C}_{\mathrm{D}}$ or $\mathrm{z}_{0}$ on $\mathrm{U}_{10 \mathrm{~m}}$ for fetch-limited conditions; this issue was mentioned in the introduction, as well as in Fig. 2 (blue circles). Further investigation is needed regarding the description of wave conditions for input to the atmospheric modeling in these conditions.

\section{6 | CONCLUSIONS}

Here we have efficiently modeled 23 years of extreme wind samples, amounting to 429 storm days, via the selective dynamical downscaling method. This was accomplished through a wind-wave modeling system, wherein the atmospheric model WRF was coupled to the wave model SWAN, with the physics of the air-sea interface handled by the wave boundary layer model (WBLM) implemented in SWAN ${ }^{23}$. This WBLMbased system effectively supersedes parameterization schemes of roughness length or drag coefficient over water for winds over $20 \mathrm{~ms}^{-1}$, where different schemes diverge significantly and fail to represent some conditions such as modeled here. The results from the coupled modeling are promising, on the atmospheric side: the variation of drag coefficient with wind speed compares well with measurements in the literature. The estimates of expected 50-year wind at $100 \mathrm{~m}$ height are generally underestimated in comparison with measurements, from both the coupled and uncoupled modeling. However, the coupled modeling tends to predict extreme winds which are stronger and closer to observations than those from uncoupled modeling, particularly for strong wind affected areas.

Acknowledgement. This paper is mainly supported by the Danish ForskEL project XWiWa (PSO-12020) and partially by the EU-CEASELESS project (H2020-EO-2016-730030-CEASELESS). We thank Ørsted (formerly DONG energy) and Vattenfall for measurements from Horns Rev and thank EU-Mermaid project for the data access to FINO 1, FINO 2 and FINO 3. The CFSR data are obtained from http://rda.ucar.edu/datasets. The bathymetry data are obtained from the EMODnet Bathymetry portal and land cover data are from https://land.copernicus.eu/pan-european/ corine-land-cover. The authors have no conflict of interest to declare.

\section{References}

1. International Standard IEC 61400-1. ISBN 2-8318-8161-7: International Electrotechnical Commission; 2007. 
2. Pryor S. C., Barthelmie R. J., Clausen N. E., Drews M., Mackeller N., Kjellström E.. Analysis of possible changes in intense and extreme wind speeds over northern Europe under climate change scenarios. Clim. Dyn.. 2010;.

3. Hofherr T., Kunz M.. Extreme wind climatology of winter storms in Germany. Clim. Res.. 2010;41:105-123.

4. Kunz M., Mohr S., Rauthe M., Lux R., Kottmeier Ch.. Assessment of extreme wind speeds from regional climate models - Part 1: Estimation of return values and their evaluation. Nat. Hazards Earth Syst. Sci.. 2010;10:907-922.

5. Skamarock W.C.. Evaluating mesoscale NWP models using kinetic energy spectra. Mon Weather Rev. 2004;132:3019-3032.

6. Skamarock W.C.. Kinetic Energy Spectra and model filters. Lecture Note in Numerical Techniques for Global Atmospheric Models. 2011;80:495512.

7. Frehlich R., Sharman R.. The use of structure functions and spectra from numerical model output to determine effective model resolution. Monthly Weather Rev.. 2008;136:1537-1553.

8. Larsén X. G., Ott S., Badger J., Hahmann A. H., Mann J.. Recipes for correcting the impact of effective mesoscale resolution on the estimation of extreme winds. J. Appl. Meteorol. Climat.. 2012;51(3):521-533.

9. Larsén X. G., Badger J., Hahmann A. N., Mortensen N. G.. The selective dynamical downscaling method for extreme-wind atlases.. Wind Energy. 2013;16:1167-1182.

10. Kelly Mark, Gryning Sven-Erik. Long-Term Mean Wind Profiles Based on Similarity Theory. Boundary-Layer Meteorology. 2010;136(3):377-390.

11. Powell M. D., Vickery P. J., Reinhold T. A.. Reduced drag coefficient for high wind speeds in tropical cyclones. Nature. 2003;422:279-283.

12. Edson J.B., Jampana V., R.A.WELLER, et al. On the exchange of momentum over the open sea. Journal of Geophysical Oceanography. 2013;43:1589-1610.

13. Mahrt L., Vickers D., Howell J., et al. Sea surface drag coefficients in the Risø air sea experiment. Journal of Geophysical Research. $1996 ; 101: 14327-14335$

14. Vickers D., Mahrt L.. Fetch limited drag coefficient. Boundary-Layer Meteorol.. 1997;85:53-79.

15. Fairall C.W., Bradley E.F., Hare J.E., Grachev A.A., Edson J.B.. Bulk parameterization of air-sea fluxes: Updates and verification for COARE algorithm. Journal of Climate. 2003;16:571-591.

16. Donelan M.A., Dobson F.W., Smith S.D., Anderson R.J.. On the dependence of sea surface roughness on wave development. J. Phys. Oceanogr.. $1993 ; 23: 2143-2149$.

17. Soloviev A. V., Lukas R., Donelan M. A., Huas B. K., Ginis I.. The air-sea interface and surface stress under tropical cyclones. Nature. $2014 ; 4: 5306$.

18. Taylor P., Yelland M. J.. The dependence of sea surface roughness on the height and steepness of the waves. Journal of Physical Oceanography. 2001;31:572-590. 
19. Oost W.A., Komen G. J., Jacobs C., Oort C. Van. New evidence for a relation between wind stress and wave age from measurements during ASGAMAGE. Boundary-layer Meteorol.. 2002;102:409-438.

20. Drennan W., Zhang J. A., French J. F., McCormick C., Black P. G.. Turbulent fluxes in the hurricane boundary layer. Part II: latent heat flux. Journal of Atmospheric Sciences. 2007;64:1103-1115.

21. Liu B., Liu H., Xie L., Guan C., Zhao D.. A coupled atmosphere-wave-ocean modeling system: simulation of the intensity of an idealized tropical cyclone. Monthly Weather Review. 2011;139:132-152.

22. Fan Y., Lin S., Held I. M., Yu Z., Tolman H. L.. Global ocean surface wave simulation using a coupled atmosphere-wave model. Journal of Climate. $2012 ; 25: 6233-6252$.

23. Du J., Bolaños R., Larsén X. G.. The use of a wave boundray layer model in SWAN. Journal of Geophysical Research - Ocean. 2017;122:42-62.

24. Du J.. Coupling atmospheric and ocean wave models for storm simulation. DTU Wind Energy PhD-0074(EN). 2017;.

25. Senet C., Fischer J., Outzen O., Herklotz K., Klein H.. Remote sensing and in situ sea state instrument comparisons at the research platform FINO 1 in the German Bight. Geoscience and Remote Sensing Symposium (IGARSS), IEEE International. 2012;:7625-7628.

26. FINO1 . http://www.fino1.de/en/research/measurement/117\$-\$meteorological-measurements. : ; .

27. FINO2 . http://www.fino2.de/en/research/meteorology.html. : ; .

28. FINO3 . http://www.fino3.de/en/research/meteorology. : ; .

29. Beeken A., Kindler D.. FINO - Technical and Environmental Research Platforms for the Benefit of the Offshore Industry. : ; 2011.

30. Peña A., Floors R., Wagner R., et al. Ten years of boundary-layer and wind-power meteorology at Høvsøre, Denmark. Boundary-Layer Meteorol.. 2016;158:1-26.

31. Larsén X. G., Larsen S. E., Petersen E. L.. Full-scale spectrum of boundary-layer winds. Boundary-Layer Meteorol. 2016;159:349-371.

32. Larsén X. G., Vincent C. L., Larsen S.. Spectral structure of the mesoscale winds over the water. Q. J. R. Meteorol. Soc.. 2013;139:685-700.

33. Saint-Drenan Y.. Comparison of different Charnock models for the determination of the vertical wind profile. : Fraunhofer Institut für Windenergie und Energiesystemtechnik IWES, RD Division Energy Economy and Grid Operation, Königstor 59, 34119 Kassel, Germanyhttp://www.hrensemble.net/public/pdf/HRensembleHR_20091221_IWES.pdf; 2009.

34. Larsén X. G., Kalogeri C., Galanis G., Kallos G.. A statistical methodology for the estimation of extreme wave conditions for offshore renewable applications. Renewable Energy. 2015;80:205-218.

35. Högström U.. Nondimentional wind and temperature profiles. Boundary Layer Meteorol.. 1988;42:55-78.

36. Stull R.. An introduction to Boundary Layer Meteorology. Atmospheric Sciences Library, Kluwer Academic Publishers; 1988. 
37. Abild J.. Application of the wind atlas method to extremes of wind climatology. Risoe-R-722(EN): Risø National LaboratoryRoskilde, Denmark; 1994.

38. Larsén X. G., Mann J., Rathmann O., Jørgensen H. E.. Uncertainties of the 50-year wind from short time series using generalized extreme value distribution and generalized Pareto distribution. Wind Energy. 2015;18:59-74.

39. Hosking J.R.M.. Estimation of the generalized extreme value distribution by the method of probability-weighted moments. Technometrics. $1985 ; 27: 251-261$.

40. Mann J., Kristensen L., Jensen N. O.. Uncertainties of extreme winds, spectra and coherences. In: Larsen , Esdahl , eds. Bridge Aerodynamics, ISBN 9054109610, Balkema: Rotterdam 1998.

41. Hansen B. O., Larsén X. G., Kelly M., et al. Extreme wind calculation applying spectral correction method - test and validation. : Wind Enery Department, Technical University of DenmarkDTU Wind Energy E-0098; 2016.

42. Du J., Larsén X. G., Bolaños R.. A coupled atmospheric and wave modeling system for storm simulations. Proceedings of EWEA Offshore Conference, Copenhagen. 2015;

43. M. Imberger. Modeling rough weather over the North Sea - using COAWST for offshore wind energy applications. DTU Wind Energy-M-0149: Technical University of Denmark; 2017.

44. Thompson G., Rasmussen R. M., Manning K.. Explicit forecasts of winter precipitation using an improved bulk microphysics scheme. Part-I: Description and sensitivity analysis. Mon. Weather Rev.. 2004;132:519-542.

45. lacono M. J., Delamere J. S., Mlawer E. J., Shephard M. W., Clough S. A., Collins W. D.. Radiative forcing by long-lived greenhouse gases: Calculations with the AER radiative transfer models. Journal of Geophysical Research. 2008;113:13013.

46. Nakanishi M., Niino H.. Development of an improved turbulence closure model for the atmospheric boundary layer. J. Meteorol. Soc. Jpn. 2009;87:895-912.

47. Kain J. S., Fritsch J. M.. Convective parameterization for mesoscale models: The Kain-Fritsch scheme. The representation of cumulus convection in numerical models, Meteor. Monogr.. Ameri. Meteor. Soc.. 1993;24:165-170.

48. Ratsimandresy A.W., Sotillo M.G., Albiach J.C. Carretero, Fanjul E., Hajji H.. A 44-year high-resolution ocean and atmospheric hindcast for the Mediterranean Basin developed within the HIPOCAS Project. Coastal Engineering. 2008;55:827-842.

49. Janssen P. a. E. M., Lionello P., Zambresky L.. On the Interaction of Wind and Waves. Philosophical Transactions of the Royal Society A: Mathematical, Physical and Engineering Sciences. 1989;329(1604):289-301.

50. Jensen R E, Cardone V J. Performance of third generation wave models in extreme hurricanes. 9th International Workshop on Wave .... $2006 ; 54: 258$. 
51. Moon II J., Ginis Isaac, Hara Tetsu. Effect of surface waves on Charnock coefficient under tropical cyclones. Geophysical Research Letters. 2004;31(20):1-4.

52. Moon II-Ju, Kwon Jae-II, Lee Jong-Chan, et al. Effect of the surface wind stress parameterization on the storm surge modeling. Ocean Modelling. 2009;29(2):115-127.

53. Hara Tetsu, Belcher Stephen E. Wind forcing in the equilibrium range of wind-wave spectra. Journal of Fluid Mechanics. 2002;470:223-245.

54. Hara T, Belcher S E. Wind profile and drag coefficient over mature ocean surface wave spectra. Journal of Physical Oceanography. 2004;34(11):2345-2358.

55. Mann J., Hansen S. O.. Én storm gør ingen storm. Vejret. 2000;82:28-34.

56. Larsén X. G., Bolaños R., Du J., et al. Final report for X-WiWa project: Extreme winds and waves for offshore turbines. Report DTU Wind Energy E-0154, ISBN: 978-87-93549-22-7, http://www.xwiwa.dk/publications/project-report. 2017;.

57. Dagestad K.-F., Horstmann J., Mouche A., et al. Wind retrieval from synthetic aperture radar - an overview. Proceedings of SEASAR 2012 Advances in SAR Oceanography, Tromsø Norway. 2012;.

58. Bakan S., Schwarz E.. Cellular convection over the north-eastern atlantic. International journal of climatology. 1992;12:353-367.

59. Larsén X. G., Larsen S. E., Petersen E. L., Mikkelsen T.. Turbulence characteristics of wind speed in the presence of open cells - a case study. Boundary-Layer Meteorol., https://doi.org/10.1007/s10546-019-00425-8. 2019;.

60. Vincent C. L.. Mesoscale wind fluctuations over Danish waters. Risø-PhD-70(EN): Risø DTU, National Laboratory for Sustainable EnergyRoskilde, Denmark; 2010.

61. Vincent C. L., Hahmann A. N., Kelly M. C.. Idealized mesoscale model simulations of open cellular convection over the sea. Boundary-Layer Meteorol. 2012;142:103-121.

62. Larsén X. G., Du J., Bolaños R., Larsen S.. On the impact of wind on the development of wave field during storm Britta. Ocean Dynamics, https://doi.org/10.1007/s10236-017-1100-1. 2017;67(11):1407-1427.

63. Zijlema M., Van Vledder G. Ph, Holthuijsen L. H.. Bottom friction and wind drag for wave models. Coastal Engineering. 2012;65:19-26. 
TABLE 1 Sites and their coordinates, data period and coverage and the height where data are analyzed.

\begin{tabular}{lllll}
\hline Site & Coordinates & Period & Data length (years) & Height $(\mathrm{m})$ \\
\hline FINO1 & $6.588^{\circ} \mathrm{E}, 54.014^{\circ} \mathrm{N}$ & $2004-2017$ & 14 & 100 \\
FINO2 & $13.1542^{\circ} \mathrm{E}, 55.007^{\circ} \mathrm{N}$ & $2008-2017$ & 10 & 102 \\
FINO3 & $7.1583^{\circ} \mathrm{E}, 55.195^{\circ} \mathrm{N}$ & $2010-2017$ & 8 & 100 \\
Høvsøre & $8.15^{\circ} \mathrm{E}, 56.433^{\circ} \mathrm{N}$ & $2005-2017$ & 13 & 100 \\
M2 & $7.875^{\circ} \mathrm{E}, 55.508^{\circ} \mathrm{N}$ & $2000-2005$ & 6 & 62 \\
\hline
\end{tabular}


TABLE $2 \mathrm{U}_{50} \pm \sigma\left(\mathrm{U}_{\mathrm{T}}\right)\left(\mathrm{ms}^{-1}\right)$ from measurements and from modeling (1994-2016).

\begin{tabular}{lllll}
\hline Site & Measurements & Measurements & coupled modeling & non-coupled modeling \\
& PMM & POT & & \\
\hline FINO 1 (100m) & $41.1 \pm 2.9$ & $41.2 \pm 2.7$ & $39.5 \pm 2.1$ & $38.1 \pm 1.9$ \\
FINO 2 (102m) & $35.3 \pm 2.2$ & $38.2 \pm 2.1$ & $38.6 \pm 2.3$ & $37.3 \pm 2.0$ \\
FINO 3 (100m) & $40.2 \pm 3.5$ & $43.3 \pm 3.0$ & $43.0 \pm 2.5$ & $41.6 \pm 1.9$ \\
Høvsøre(100m) & $44.1 \pm 3.8$ & $45.1 \pm 3.2$ & $44.6 \pm 3.2$ & $42.0 \pm 2.6$ \\
M2 (62 m) & $44.8 \pm 6.3$ & $44.3 \pm 4.7$ & $40.0 \pm 2.5$ & $40.0 \pm 2.6$ \\
\hline
\end{tabular}


TABLE $3 \mathrm{U}_{50} \pm \sigma\left(\mathrm{U}_{\mathrm{T}}\right)\left(\mathrm{ms}^{-1}\right)$ from measurements and from modeling (overlapping period). 2017 data are not used.

\begin{tabular}{lllll}
\hline Site & Measurements & Measurements & coupled modeling & non-coupled modeling \\
& PMM & POT & & \\
\hline FINO 1 (100m) & $41.0 \pm 3.0$ & $42.0 \pm 2.6$ & $39.1 \pm 2.8$ & $37.1 \pm 2.3$ \\
FINO 2 (102m) & $35.5 \pm 2.4$ & $38.3 \pm 2.2$ & $36.1 \pm 3.0$ & $35.8 \pm 2.9$ \\
FINO 3 (100m) & $40.1 \pm 3.7$ & $43.9 \pm 3.3$ & $45.5 \pm 5.6$ & $41.9 \pm 4.4$ \\
Høvsøre(100m) & $44.1 \pm 4.4$ & $45.1 \pm 2.9$ & $45.5 \pm 4.5$ & $42.6 \pm 3.7$ \\
M2 (62 m) & $44.8 \pm 6.3$ & $44.3 \pm 4.7$ & $43.0 \pm 4.2$ & $43.0 \pm 5.2$ \\
\hline
\end{tabular}


TABLE $4 \mathrm{U}_{50 \mathrm{yr}} \pm \sigma\left(\mathrm{U}_{\mathrm{T}}\right)\left(\mathrm{ms}^{-1}\right)$ from CFSR 10-m wind speed calculated from three periods.

\begin{tabular}{llll}
\hline Site & $1979-2016$ & $1994-2016$ & $2007-2016$ \\
\hline FINO 1 & $29.8 \pm 2.3$ & $29.7 \pm 2.8$ & $30.6 \pm 4.9$ \\
FINO 2 & $27.9 \pm 2.5$ & $28.0 \pm 3.3$ & $26.0 \pm 3.5$ \\
FINO 3 & $31.8 \pm 2.7$ & $32.0 \pm 3.7$ & $30.0 \pm 4.2$ \\
Høvsøre & $30.3 \pm 3.4$ & $30.3 \pm 4.5$ & $30.9 \pm 7.1$ \\
M2 & $32.4 \pm 3.1$ & $31.9 \pm 4.0$ & $29.0 \pm 4.2$ \\
\hline
\end{tabular}




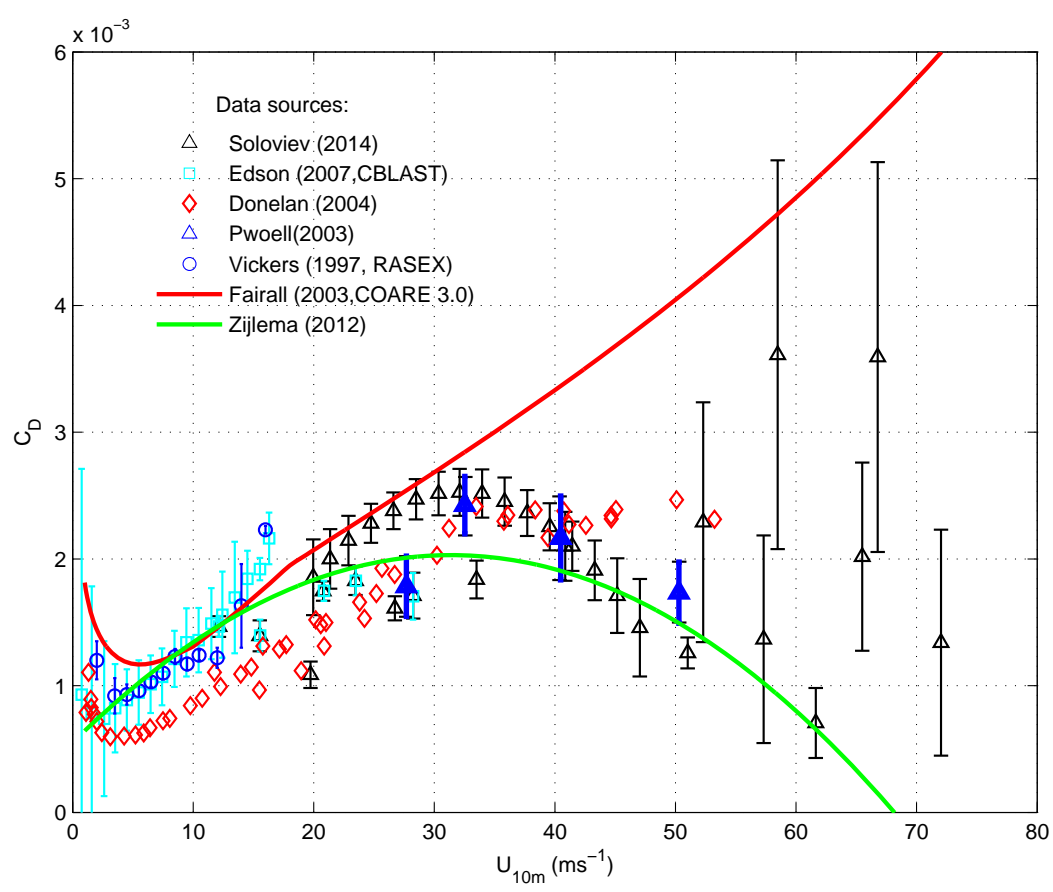

FIGURE 1 Drag coefficient $C_{D}$ as a function of wind speed at $10 \mathrm{~m}$ height $\left(\mathrm{U}_{10 \mathrm{~m}}\right)$, from aggregated measurements and literature (symbols). Zijlema is a simplified functional relation $\mathrm{C}_{\mathrm{D}}\left(\mathrm{U}_{10 \mathrm{~m}}\right)$ for all measurements ${ }^{63}$; Fairall is a based on Eqs. 1-2, with Charnock coefficient $\alpha_{\mathrm{Ch}}$ calibrated using measurements from COARE. ${ }^{15}$ 


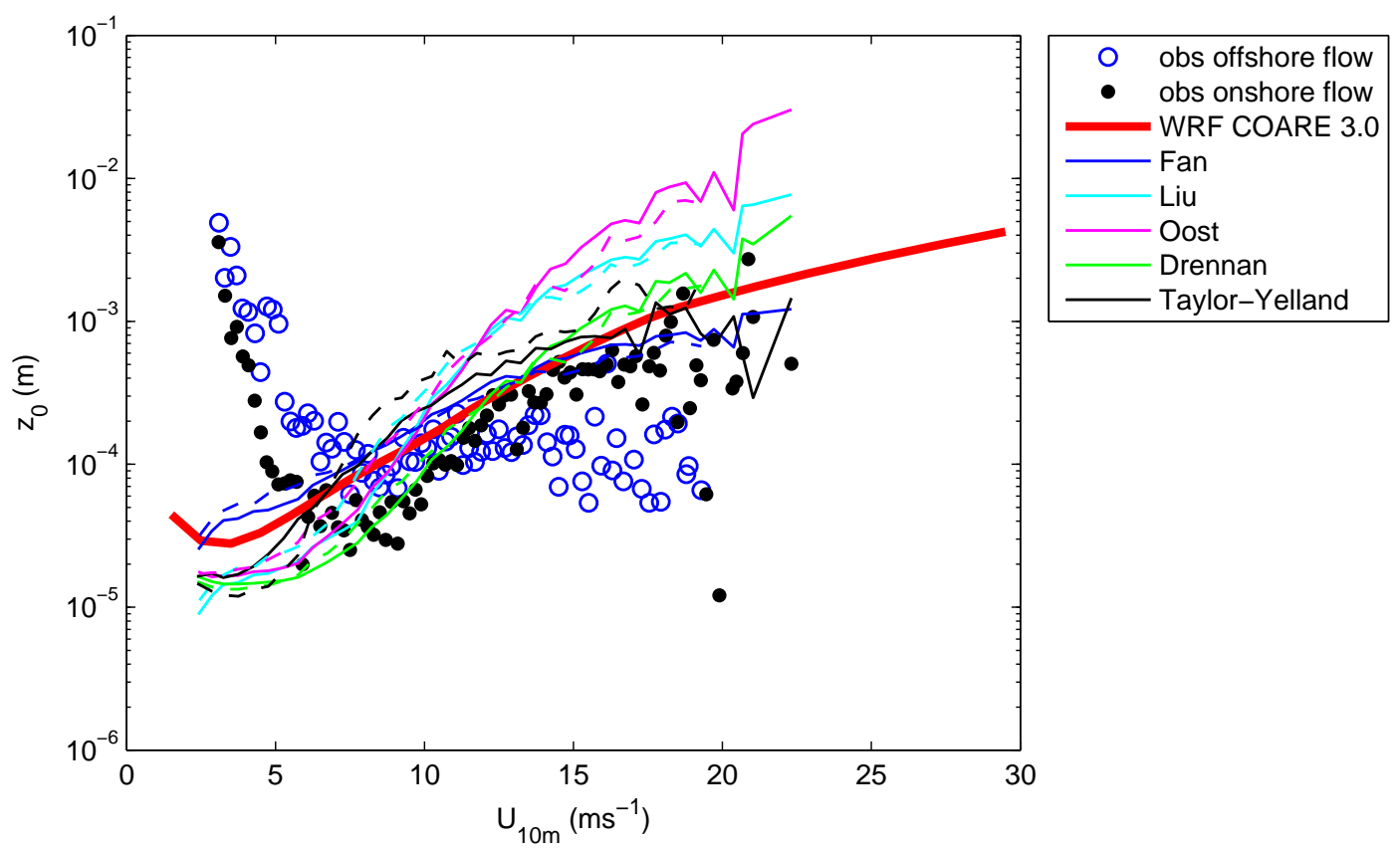

FIGURE 2 Roughness length $\mathrm{z}_{0}$ as a function of wind speed at $10 \mathrm{~m}$ above surface level $\left(\mathrm{U}_{10 \mathrm{~m}}\right)$. Measurements from Horns Rev $\mathrm{M} 2$ are shown as blue circles for flow towards offshore (shallow/land) conditions, and black dots for flow towards onshore (open/deep water) conditions. Several models are applied corresponding to the wave parameters calculated from measurements at M2, also for onshore (solid lines) and offshore (dashed lines) conditions.

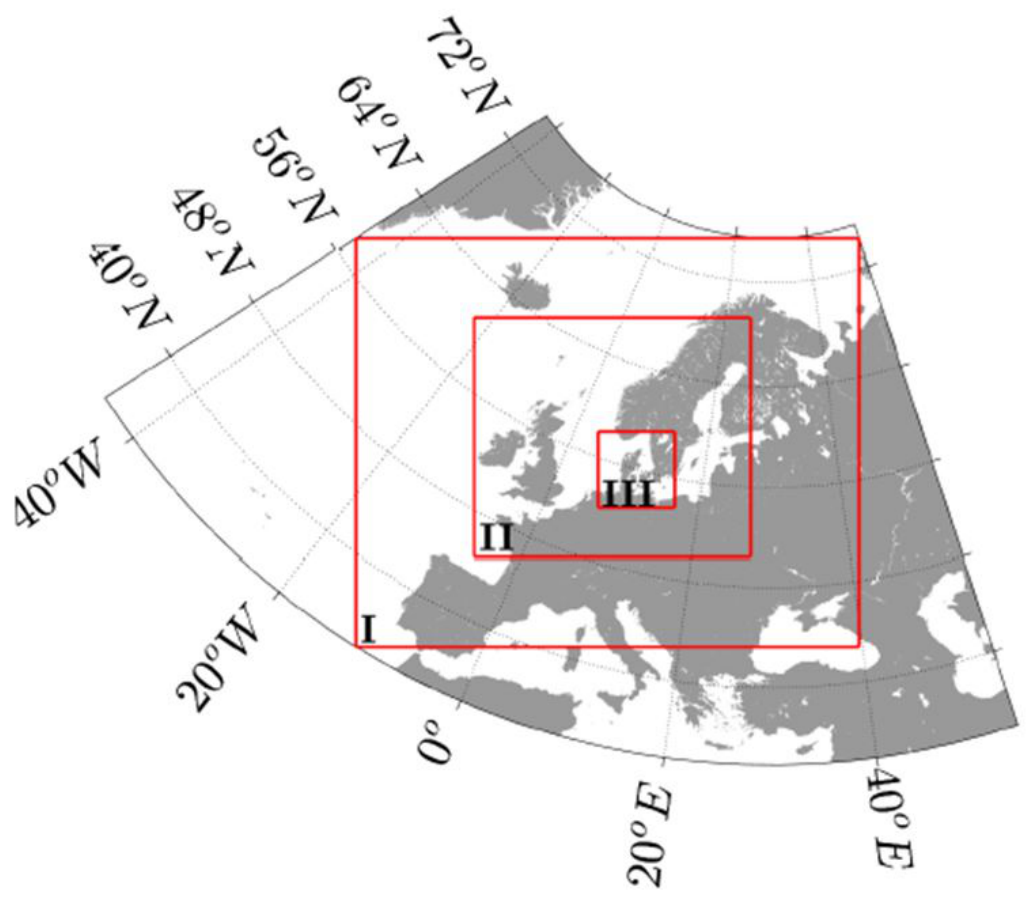

FIGURE 3 Three nested model domains with resolutions of $18 \mathrm{~km}, 6 \mathrm{~km}$ and $2 \mathrm{~km}$, respectively. 


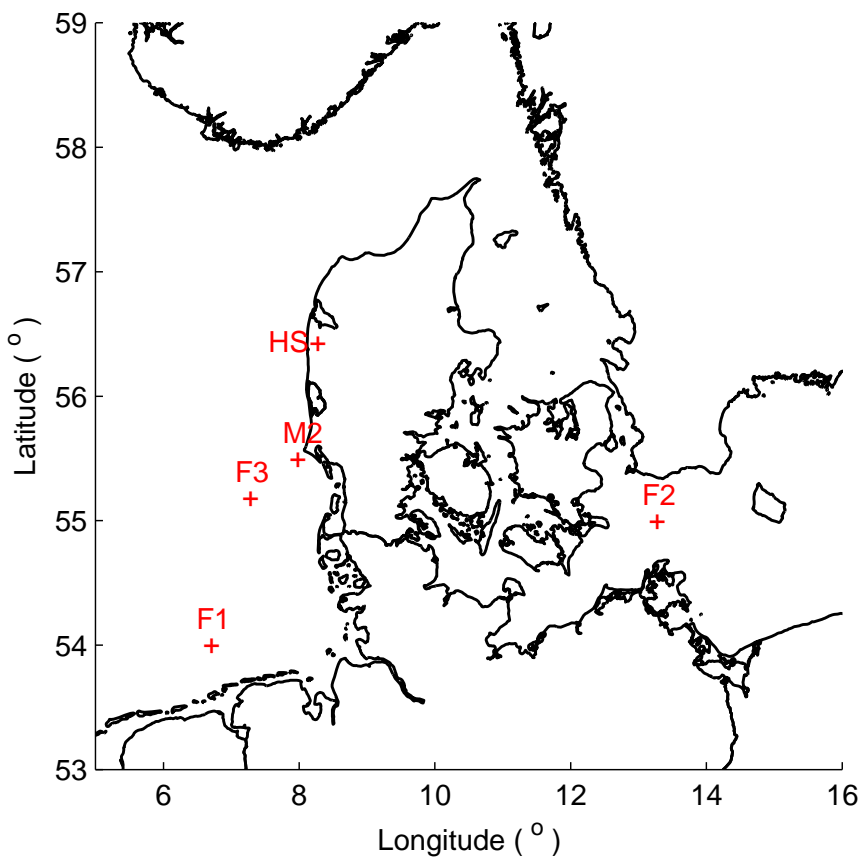

FIGURE 4 The five sites: FINO 1, 2 and 3 (F1, F2, F3, respectively), Høvsøre (HS) and Horns Rev 1 mast 2 (M2).

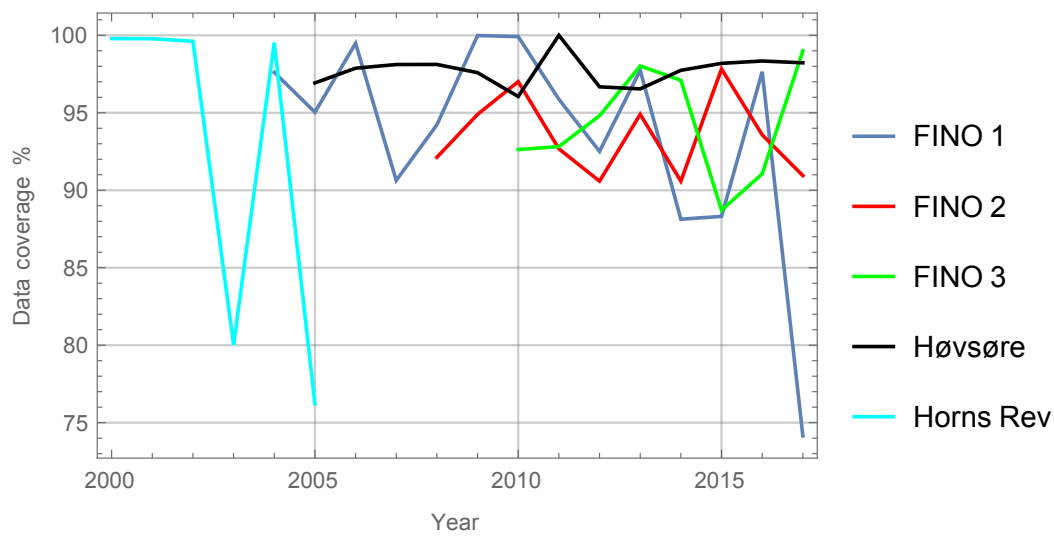

FIGURE 5 Yearly data coverage at the five sites. 
(a)

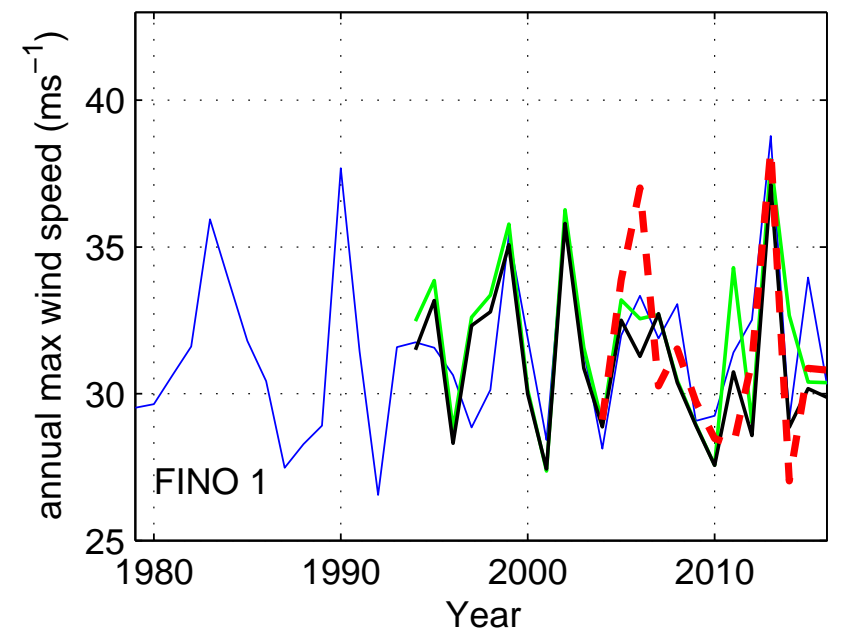

(b)

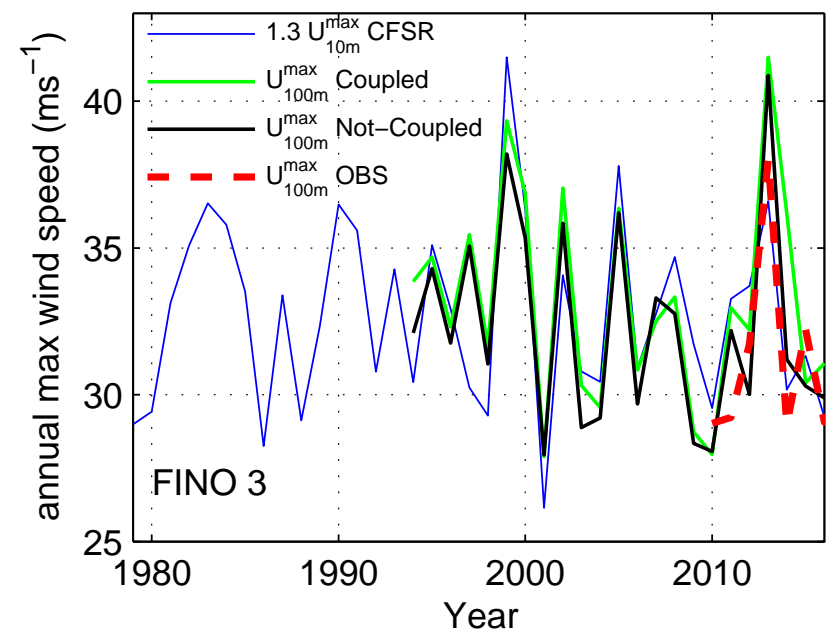

FIGURE 6 Examples of the inter-annual variation of the annual wind maxima from the CFSR 10-m wind speed, coupled modeling, non-coupled modeling and measurements. (a) FINO 1. (b) FINO 3 

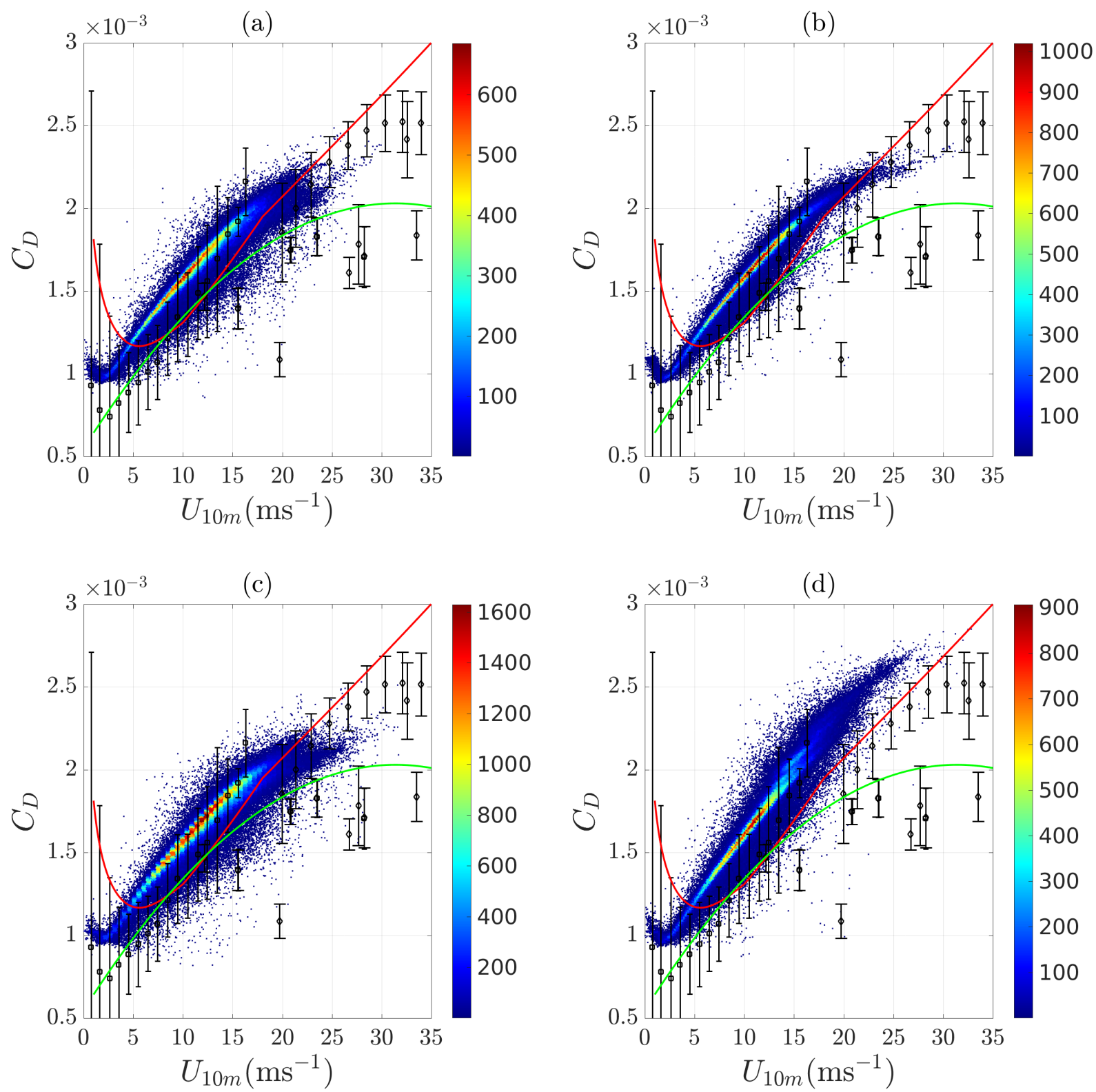

FIGURE 7 Joint distribution of $C_{D}$ and $U_{10 m}$ from all simulations. The dots are from the coupled modeling, with the color bars showing the number of data points for each dot. The curves and error-bars are from Fig. 1, used here as reference. (a) FINO 1; (b) FINO 2; (c) FINO 3; and (d) M2. 

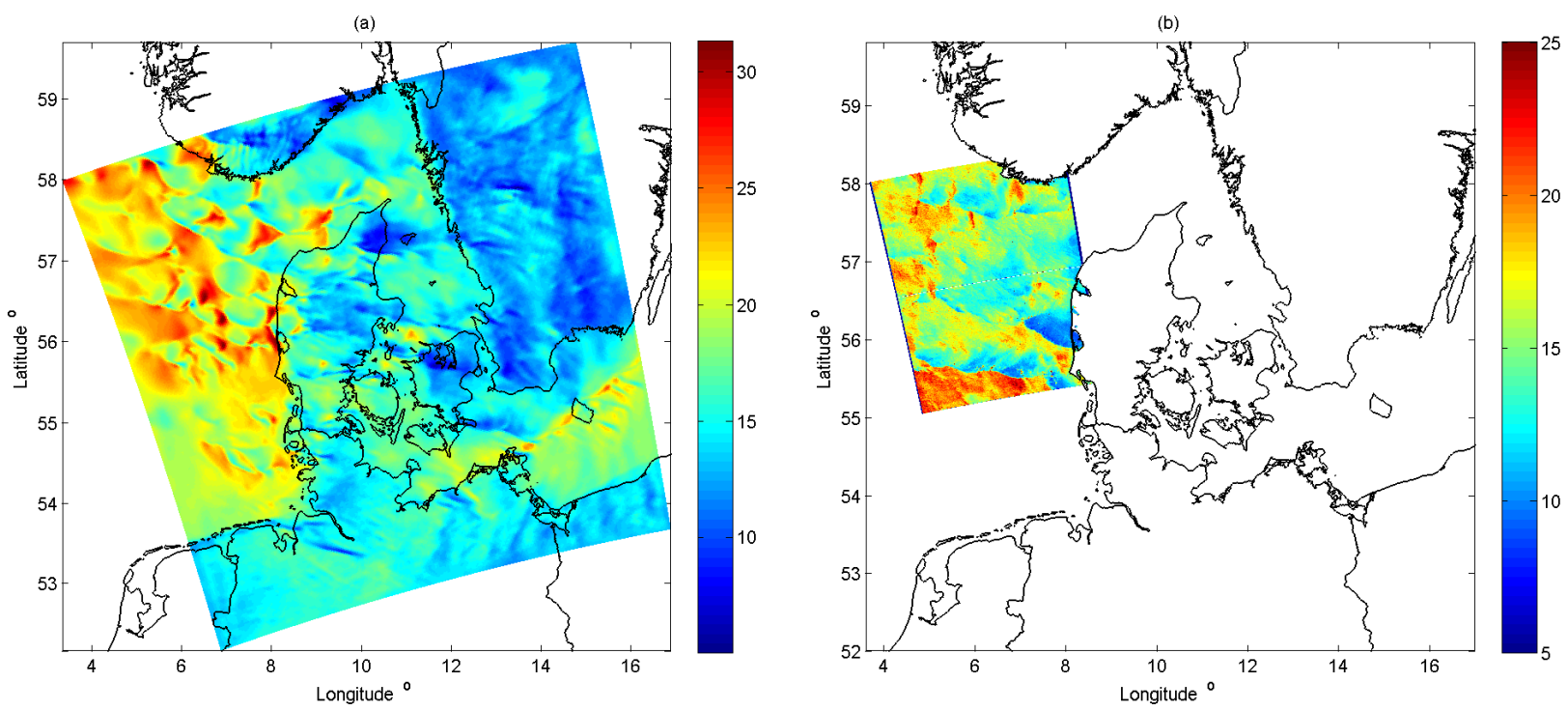

FIGURE 8 An example of the 10-m wind fields from (a) modeling in the presence of open cells at 18:00 on 2016-12-24. (b) Satellite data from Sentinel-1B by ESA covering part of the area in (a) at 17:17 on 2016-12-24 (obtained at https://satwinds.windenergy.dtu.dk/). 

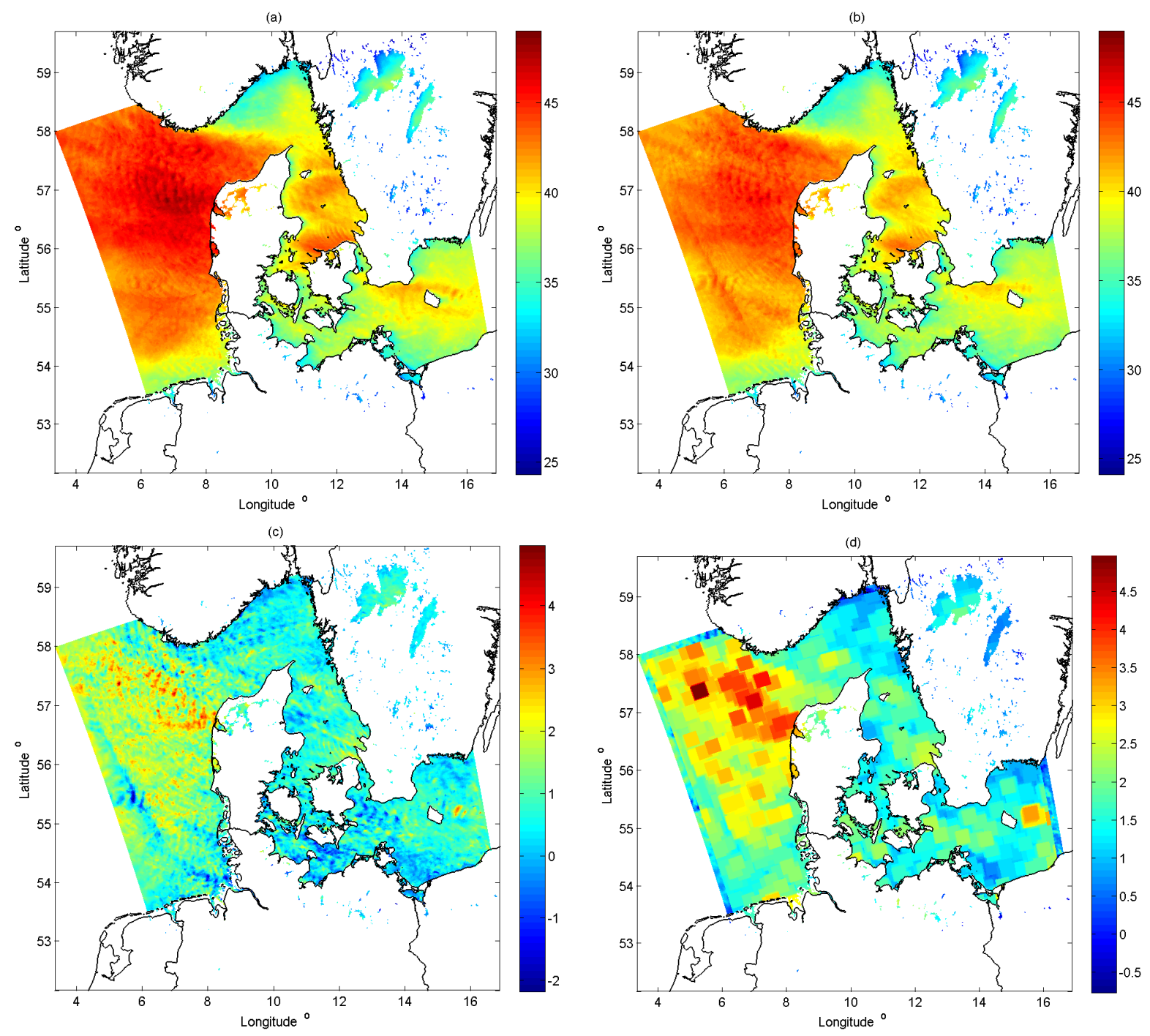

FIGURE 9 The 50-year winds at 100 m over waters around Denmark: (a) from WRF-WBLM-SWAN modeling; (b) from WRF modeling; (c) difference of a minus b; (d) maximum of wind speed difference over 13 by 13 grid points around each grid point (apart from the boundaries). 
(a)

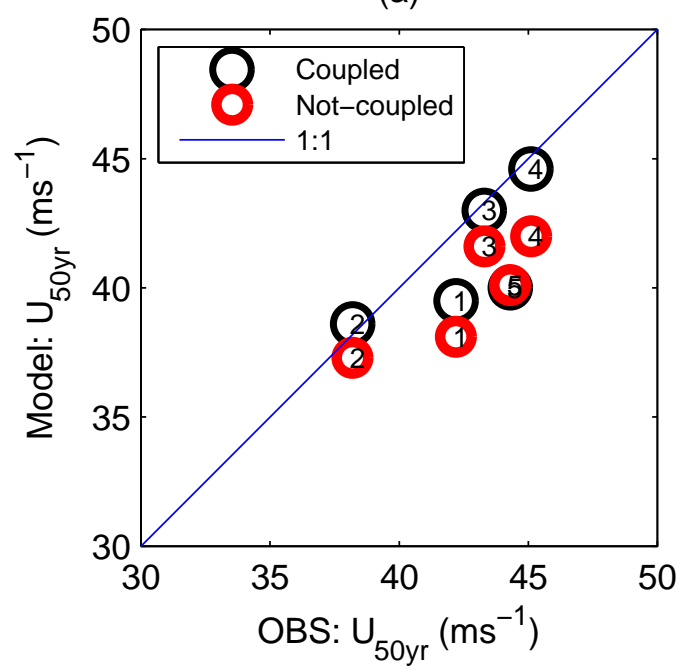

(b)

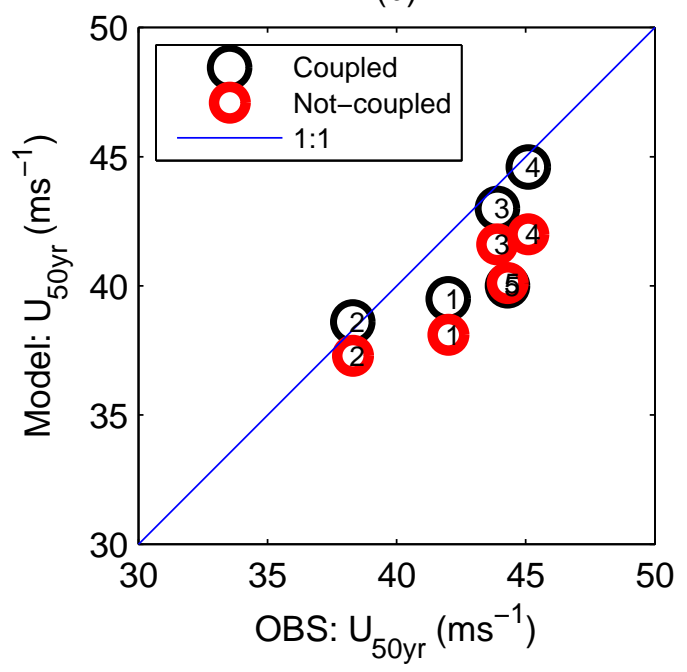

FIGURE 10 Comparison of modeled (y-axis) vs. measured ( $x$-axis) $U_{50}$, from coupled (black circles) and unn-coupled (red circles) modeling at 5 stations: No. 1: FINO 1; No. 2: FINO 2; No. 3: FINO 3; No. 4: Høvsøre; No. 5: M2. The values are also presented in Tables 2-3. The measurement height is $100 \mathrm{~m}$ at FINO 1, 2, 3 and Høvsøre, and 62 m at Horns Rev M2. Left (a): using entire modeled dataset; right (b): using model data overlapping with measurements. 